\title{
A pilot factorial randomised cohort trial of manual therapy or acupuncture for low back pain
}

Vivienne C Dascanio*, Yvonne Birks, David Torgerson

From Clinical Trials Methodology Conference 2011

Bristol, UK. 4-5 October 2011

\section{Background}

Randomised control clinical trials of acupuncture have been hampered by the challenges of assessing it as a complex intervention. Controlling for and separating placebo effects whilst identifying its efficacy as a treatment can be difficult [1]. The comparison of acupuncture to other complex interventions has been recommended to assess the effectiveness of acupuncture against other interventions [2].

The objective of this pilot trial is to investigate the feasibility of undertaking a novel randomised cohort design study with a nested factorial RCT, investigating acupuncture alone versus manual therapy alone versus a combination of acupuncture and manual therapy versus usual care.

The pilot will investigate recruitment rates to allow for planning a full-scale trial, identify any compliance issues and strategies for reducing these in a full-scale trial and assess patient's acceptance and therapist delivery of combined therapies for the treatment of their LBP.

\section{Methods}

The study will follow a randomised cohort trial design and participants from the cohort will be selected to participate in the pilot trial. The use of this design as a recruitment method for nested trials is relatively new methodology but the cohort design has been suggested as an effective method for the use with chronic conditions [3] and its potential for minimising attrition. Attrition is one of the major threats to the internal validity of any trial. The design of this trial specifically

\footnotetext{
* Correspondence: Vcf500@york.ac.uk

York Trials Unit, Department of Health Sciences, ARRC Building, University of York, Heslington, York, YO10 5DD, UK
}

reduces that threat [4]. Using a randomised cohort design will provide a 'run-in period' of three months, from collecting baseline data to the first set of outcome data. Only participants who return their three monthly questionnaires will be eligible for randomisation to the pilot trial. As the majority of attrition occurs at the first period of follow-up in an RCT, it is expected subsequent attrition, after randomisation, to be minimal [4].

The factorial pilot RCT will investigate the treatment of low back pain with Acupuncture vs Manual Therapy vs Acupuncture and manual therapy vs Usual GP care. All interventions will be delivered by a chartered physiotherapist.

\section{Results and conclusions}

Recruitment and retention rates will be presented. The acceptability and feasibility of the design for use with complex interventions and in a common musculoskeletal condition will be discussed.

\section{Acknowledgements \\ NIHR Programme grant project. Funding applicant Dr Hugh MacPherson, Professor David Torgerson. \\ Small project grant award from Acupuncture Association of Chartered Physiotherapists (AACP).}

Published: 13 December 2011

\section{References}

1. Lundeberg T, L I, Sing A, Naslund J: Is placebo acupuncture what it is intended to be? Evidence-Based Complementary and Alternative Medicine 2011, 1-5, Article ID 932407, 5 pagesdoi:10.1093/ecam/nep049.

2. Furlan A, et al: Complementary and Alternative Therapies for Back Pain II. University of Ottawa Evidence-based Practice Center under Contract No. 2902007-10059-I (EPCIII) Agency for Healthcare Research and Quality: Rockville, MD; 2010

\section{C) Biomed Central}


3. Grant J, et al: The North West Adelaide Health Study: detailed methods and baseline segmentation of a cohort for selected chronic diseases. Epidemiologic Perspectives \& Innovations 2006, 3(1):4.

4. Relton C, et al: Rethinking pragmatic randomised controlled trials: introducing the "cohort multiple randomised controlled trial" design. BMJ 2010, 340:1066.

doi:10.1186/1745-6215-12-S1-A150

Cite this article as: Dascanio et al:: A pilot factorial randomised cohort trial of manual therapy or acupuncture for low back pain. Trials 2011 12(Suppl 1):A150.

Submit your next manuscript to BioMed Central and take full advantage of:

- Convenient online submission

- Thorough peer review

- No space constraints or color figure charges

- Immediate publication on acceptance

- Inclusion in PubMed, CAS, Scopus and Google Scholar

- Research which is freely available for redistribution

Submit your manuscript at www.biomedcentral.com/submit 